\title{
Review of septic arthritis throughout the antibiotic era
}

\author{
J. H. NEWMAN \\ From the Nuffield Orthopaedic Centre, Oxford
}

\begin{abstract}
Newman, J. H. (1976). Annals of the Rheumatic Diseases, 35, 198-205. Review of septic arthritis throughout the antibiotic era. 134 patients with septic arthritis who have been treated at the Nuffield Orthopaedic Centre during a 30-year period have been reviewed. There has been little change in the overall incidence during the last 20 years, but recently the disease has become more common among the elderly and patients tend to be less ill on presentation. The problems and necessity of rapidly establishing a diagnosis are stressed. Overall, $70 \%$ attained a good result though infection in infants' hips and all joints in the elderly carried a poor prognosis. Once a good result was achieved the joint did not deteriorate with the passage of time.
\end{abstract}

Several recent but contradictory studies of septic arthritis have concluded that the pattern of the disease is changing. Nelson (1972) reports a steadily rising incidence in children, while Kelly, Martin, and Coventry (1970) state that septic arthritis is no longer primarily a disease of children, but is frequently seen in the elderly. A high incidence of Haemophilus influenzae infection has been found by Almquist (1970) and by Lindgren and Lindberg (1973), but Paterson (1970) has found this to be uncommon.

None of these series covered more than 15 years. The present paper reports a review of the cases seen at Oxford over the last $\mathbf{3 0}$ years, which more or less coincides with the antibiotic era. The pattern of the disease has been studied to detect any changes and an attempt has been made to assess the factors which influence the long-term effects of joint infection.

\section{Material}

137 infected joints in 134 patients seen during the last 30 years form the basis of this study. Joint infections following a penetrating wound or operation are excluded and only those involving the six major peripheral joints are considered. When $x$-rays taken during the initial period of admission showed bony changes the infection has been considered as osteomyelitis and the case excluded.

The criteria for regarding the cases as septic arthritis are shown in Table I. In 94 cases the organism was grown from the joint aspirate, while in the remainder the diagnosis was made on clinical, radiological, or histological grounds.
Table I Criteria for diagnosis of septic arthritis

(a) Organism isolated from joint

(b) Organism isolated from elsewhere

(c) No organism isolated but

(i) histological or radiological evidence of infection

(ii) turbid fluid aspirated from joint (previous antibiotics in 16)

Total

\section{Epidemiology}

The incidence of septic arthritis has changed little in the last 20 years (Table II), the increase in numbers being more or less parallel with the increase in population. However, there has been a change in age distribution. Before 1954 most patients were children, but in the last decade many more adults were seen with infected joints,

Table II Age distribution of patients with septic arthritis

\begin{tabular}{|c|c|c|c|c|}
\hline Age (years) & $1944-53$ & $1954-63$ & $1964-73$ & Total \\
\hline $\begin{array}{r}0-14 \\
15-29 \\
30-44 \\
45-60 \\
60+\end{array}$ & $\begin{array}{r}10 \\
2 \\
0 \\
2 \\
2\end{array}$ & $\begin{array}{r}23 \\
8 \\
6 \\
8 \\
5\end{array}$ & $\begin{array}{r}30 \\
14 \\
4 \\
3 \\
17\end{array}$ & $\begin{array}{l}63 \\
24 \\
10 \\
13 \\
24\end{array}$ \\
\hline Total & 16 & 50 & 68 & 134 \\
\hline
\end{tabular}


the increase being particularly striking among the elderly

Throughout the 30-year period septic arthritis has occurred more commonly in hips and knees than in other joints (Table III). During the last decade knee infections have become relatively more common. This seems to be related to the changing age incidence as children most commonly suffer from septic arthritis of the hip while the elderly appear more likely to sustain knee infections (Table IV).

Staphylococcus aureus has been the major responsible

Table III Joints affected by septic arthritis

\begin{tabular}{|c|c|c|c|c|}
\hline Joint & $1944-53$ & $1954-63$ & $1964-73$ & Total \\
\hline Hip & 11 & 24 & 26 & 61 \\
\hline Knee & 5 & 18 & 27 & 50 \\
\hline Ankle & - & 5 & 5 & 10 \\
\hline Shoulder & 一 & 1 & 5 & 6 \\
\hline Elbow & 1 & 1 & 2 & 4 \\
\hline Wrist & 1 & 2 & 3 & 6 \\
\hline
\end{tabular}

Table IV Joints affected at different ages

\begin{tabular}{|c|c|c|c|c|c|}
\hline Joint & $\begin{array}{l}0-14 \\
\text { years }\end{array}$ & $15-29$ & $30-44$ & $45-60$ & $60+$ \\
\hline Hip & 36 & 11 & 6 & 3 & 5 \\
\hline Knee & 13 & 15 & 3 & 8 & 11 \\
\hline Ankle & 9 & - & - & 1 & - \\
\hline Shoulder & 2 & - & - & - & 4 \\
\hline Elbow & 3 & - & - & 1 & - \\
\hline Wrist & - & 1 & 1 & - & 4 \\
\hline
\end{tabular}

organism throughout the last 30 years but the percentage of penicillin-resistant organisms has risen from $29 \%$ in the first 10 -year period to $59 \%$ in the last. In addition, the variety of causative organisms has increased in the last 10 years (Table V).

\section{Diagnosis}

'The patient is able to tell you of severe pain in the region of the involved joint and furthermore, that the pain is made much worse by even the slightest movement of the involved joint. Clinical signs include spasm in muscles controlling the joint, marked tenderness, and when the involved joint is superficial, an obvious effusion' (Salter 1970).

Patients frequently do not present such a florid picture with the result that a correct diagnosis is often not reached initially. The average delay in establishing a correct diagnosis in this series was 12 days and even in the last decade one-quarter of the cases remained undiagnosed for 2 weeks or more. This problem arises because even when first seen in hospital $20 \%$ of patients had more than half of the normal range of movement in the affected joint. This finding applied equally to children and adults. In addition, there has been a progressive fall in the proportion of patients who are seriously ill with septic arthritis. Patients whose temperature during the first 24 hours of hospital admission was $>39^{\circ} \mathrm{C}$ or whose initial white blood count was $>14 \times 10^{9} / 1\left(14000 / \mathrm{mm}^{3}\right)$ have been considered as 'toxic'. Using these criteria there has been a steady fall in the number of patients who are seriously ill from $69 \%$ in the first decade to $30 \%$ in the last 10 years (Table VI). The fall in toxicity has been particularly striking among children though throughout the period of the review adults have been less toxic than children.

Table V Organisms causing septic arthritis

\begin{tabular}{|c|c|c|c|c|}
\hline Organism & $1944-53$ & $1954-63$ & $1964-73$ & Total \\
\hline Staphylococcus aureus & 7 & 33 & 27 & 67 \\
\hline ( $\%$ penicillin-resistant $)$ & $29 \%$ & $48 \%$ & $59 \%$ & \\
\hline Streptococcus pyogenes & 2 & 6 & $5^{\prime 0}$ & 13 \\
\hline Staphylococcus albus & 3 & 2 & 8 & 13 \\
\hline Gram-negative bacillus & 一 & 1 & 2 & 3 \\
\hline Haemophilus influenzae & - & - & 2 & 2 \\
\hline Micrococcus & 1 & - & 1 & 2 \\
\hline Neisseria gonorrhoeae & - & - & 1 & 1 \\
\hline Mixed organisms & 1 & 1 & 2 & 4 \\
\hline Organism unknown & & & & 32 \\
\hline
\end{tabular}

Table VI Distribution of patients who were 'toxic' on admission

\begin{tabular}{|c|c|c|c|c|c|c|}
\hline & \multicolumn{2}{|c|}{$1944-53$} & \multicolumn{2}{|c|}{$1954-63$} & \multicolumn{2}{|c|}{$1964-73$} \\
\hline & Toxic & Nontoxic & Toxic & Nontoxic & Toxic & Nontoxic \\
\hline $\begin{array}{l}\text { Children } \\
\text { (0-14 years) } \\
\text { Adults }\end{array}$ & 5 & 1 & 13 & 9 & 10 & 16 \\
\hline $\begin{array}{l}\text { (15-59 years) } \\
\text { Elderly }\end{array}$ & 1 & 1 & 3 & 12 & 2 & 8 \\
\hline$(60+$ years $)$ & 1 & 1 & 1 & 5 & 4 & 12 \\
\hline
\end{tabular}

'Toxic' patients have WBC $>14 \times 10^{\circ} / 1\left(14000 / \mathrm{mm}^{3}\right)$ or temperature greater than $39^{\circ} \mathrm{C}$. 
Radiology was seldom of diagnostic aid though effusions, sometimes causing joint subluxation (Fig. 1) can often be seen. Haematological investigation showed that the total white blood count was of little diagnostic use as in $50 \%$ of cases the value was in the normal range. However, the erythrocyte sedimentation rate was raised on all except one occasion, frequently to extremely high levels (Fig. 2).

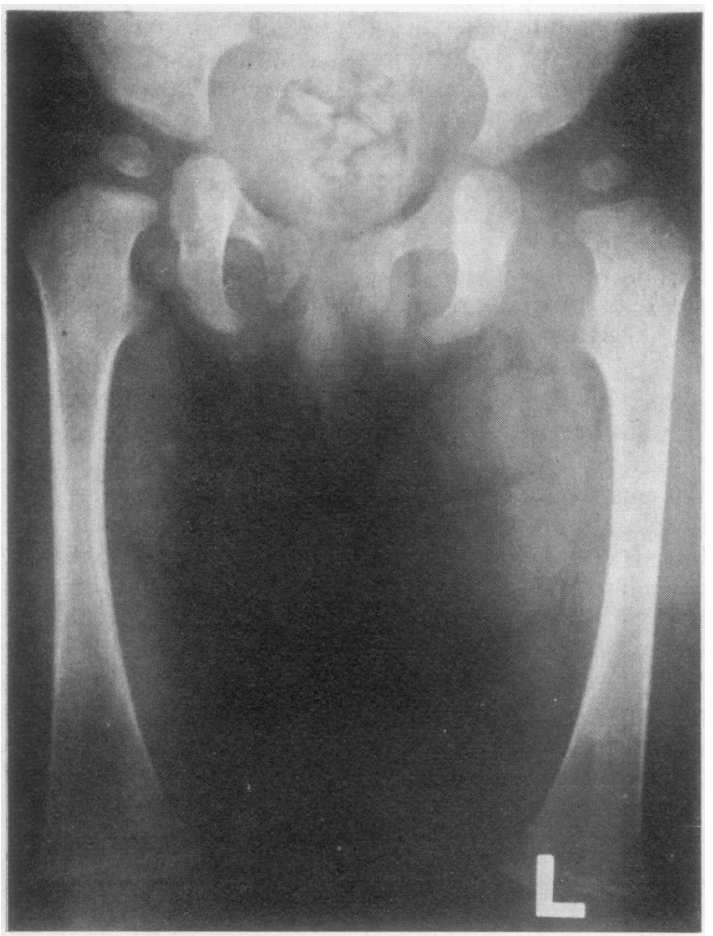

FIG. 1 X-ray showing subluxation of the left hip in a 1-year-old child. A good result was eventually achieved

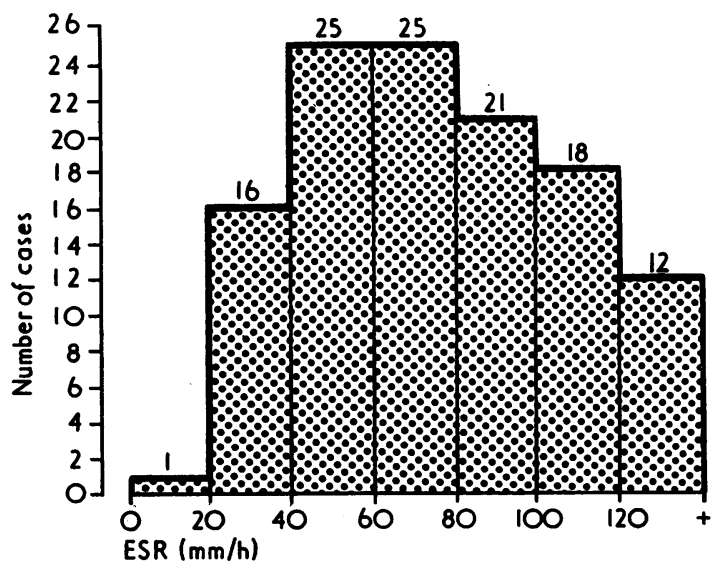

FIG. 2 Distribution of ESR in cases of septic arthritis
The diagnosis is established by examination of synovial fluid from the joint under suspicion. If frank pus is obtained there is little doubt about the joint pathology, but this is by no means always the case. Pus was obtained in $58 \%$ of cases with positive cultures. On 9 occasions organisms were grown when 'normal' or blood-stained fluid was aspirated. In $50 \%$ of cases organisms were seen on a direct Gram stain of the aspirated fluid; these organisms were always grown on subsequent culture. A total of 47 patients in the series had received antibiotics for 24 hours before aspiration of the affected joint. A positive culture was obtained in 29 of these cases although in a few instances this was obtained at arthrotomy following a negative culture of the needle aspirate.

Blood culture was performed on 54 patients and found to be positive in 19 instances. On 8 occasions the infecting organism was isolated from blood culture but not from the synovial fluid.

\section{Results}

All cases of septic arthritis seen over the last 30 years, whose initial treatment included antibiotic therapy, have been reviewed. Patients whose treatment is not yet complete have been excluded as have those in whom generalized joint disease makes assessment of the role played by sepsis impossible. There are 124 cases available for review. Half the patients have recently been examined clinically and radiologically, while the other half were unavailable and their results have been assessed by a study of the case notes and $x$-rays, supplemented by forms returned by patients or relatives. Duration of follow-up ranged from 6 months to 30 years with an average of 7 years.

The outcome of the infection has been classified simply as good or bad. When the patient has no pain in the affected joint, more than $70 \%$ of the range of movement of the opposite joint, and a normal radiograph, the outcome is considered to be good. Cases which do not satisfy these criteria are classified as bad.

There was one death in this series. Overall, $70 \%$ of cases had a good result. Infected knee joints did better than infected hip joints and in particular infection in an infant's hip joint carried a bad prognosis (Table VII).

\section{COMPLICATIONS (Table VIII)}

Bone involvement secondary to septic arthritis was seen in 25 cases. These bony lesions were not present during the initial period of treatment but were discovered subsequently, often in association with a recrudescence of the infection. This complication was associated with a bad outcome in $48 \%$ of cases and sometimes led to recurrent bouts of infection. Secondary bone infection was seen most frequently in relation to septic arthritis of the hip and could involve either the femoral neck or acetabulum 
Table VII Summary of results of septic arthritis

\begin{tabular}{|c|c|c|}
\hline & Good result & Bad result \\
\hline $\begin{array}{l}\text { Infants' hips } \\
\text { Children's hips } \\
\text { Adult hips }\end{array}$ & $\begin{array}{r}4 \\
21 \\
12\end{array}$ & $\begin{array}{l}7 \\
6 \\
9\end{array}$ \\
\hline All hips & 37 & 22 \\
\hline $\begin{array}{l}\text { Children's knees } \\
\text { Adult knees }\end{array}$ & $\begin{array}{l}10 \\
25\end{array}$ & $\begin{array}{l}1 \\
7\end{array}$ \\
\hline All knees & 35 & 8 \\
\hline $\begin{array}{l}\text { Ankles } \\
\text { Shoulders } \\
\text { Elbows } \\
\text { Wrists }\end{array}$ & $\begin{array}{l}6 \\
3 \\
4 \\
2\end{array}$ & $\begin{array}{l}3 \\
3 \\
1\end{array}$ \\
\hline Total & 87 & 37 \\
\hline
\end{tabular}

Table VIII Local complications of septic arthritis

(1) All 124 cases

Bone involvement

Recurrent infection

Bony ankylosis

Fibrous ankylosis

Limb inequality

Destructive arthritis

(2) Specific to children's hips: 0-15 years, 38 cases

Sequestration of femoral epiphysis

Absorption of femoral epiphysis

Subluxation or dislocation of hip

Coxa magna
(Fig. 3). A pseudoarthrosis had to be performed on three occasions before the infection was controlled.

Recurrent infection occurred on 13 occasions; 9 of them more than a year after the initial episode, and once after an interval of 6 years. There is no evidence to suggest that these cases were treated inadequately as all received systemic antibiotics for at least 2 months and were immobilized for at least 6 weeks.

Bony ankylosis occurred in 5 cases. Four of these involved hip joints, the youngest being in a 5-year-old child. The other case was a tibiofibula synostosis following septic arthritis of an ankle joint. In addition, 4 cases required surgical arthrodesis and one patient developed a painless fibrous ankylosis.

Limb inequality was seen in 12 children after septic arthritis of the hip had interfered with epiphyseal growth. The greatest amount of shortening seen was $11 \mathrm{~cm}$ (Fig. 4). Tibial shortening developed once after septic arthritis of an ankle, and one girl developed an overgrowth of the femur after osteomyelitis had followed septic arthritis of the knee.

Destructive arthritis. Seventeen patients developed joint changes with gross loss of cartilage and sometimes of bone. These have been classified as bad results. However, there were no cases in which the initial result appeared to be good but who developed osteoarthrosis in the ensuing years. Sixteen cases who had good initial results have been followed for more than 10 years and in all the joints remain satisfactory.

Avascular necrosis of the femoral epiphysis occurred on 8 occasions with an age range of 0-13

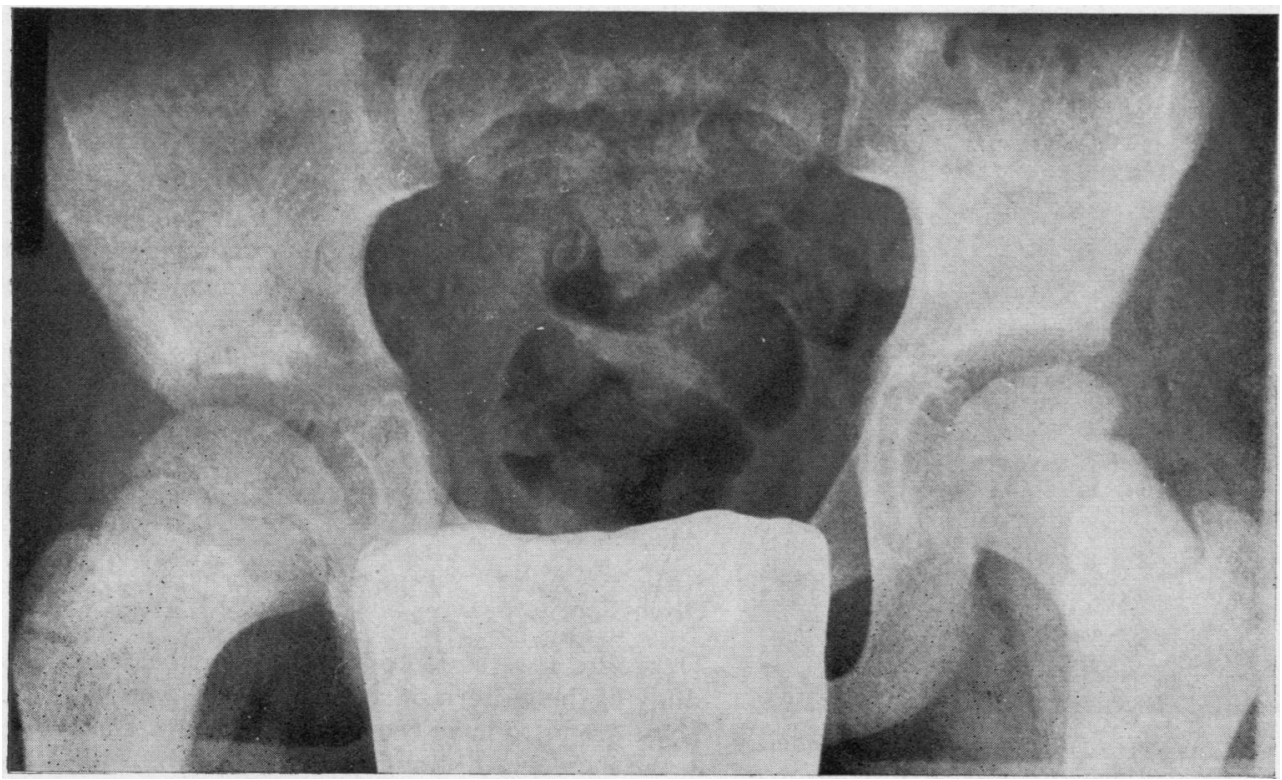

FIG. 3 X-ray showing a cavity in the right acetabulum. This was noted a year after septic arthritis and required drainage 


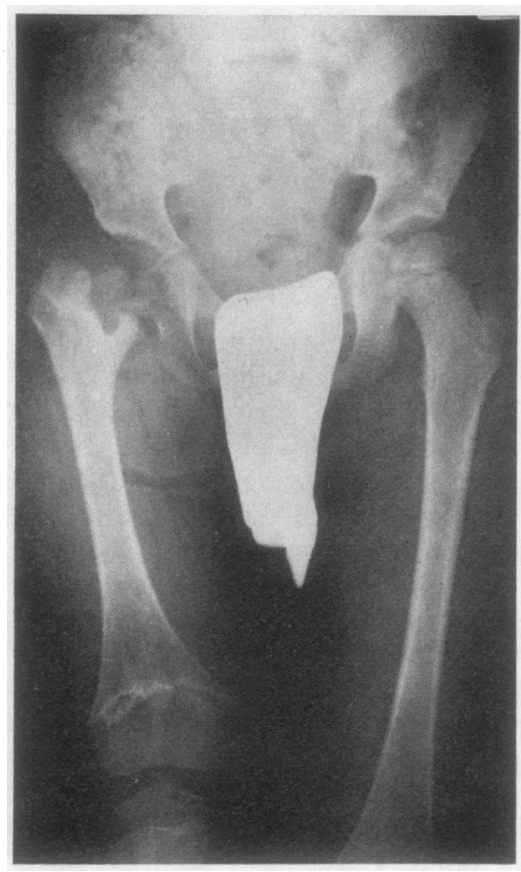

FIG. $411 \mathrm{~cm}$ of shortening in the right femur after destruction of the upper end of the femur by infantile septic arthritis

years (Fig. 5). In one patient the sequestrum was removed surgically, and in one the epiphysis was absorbed completely without reappearing. In 5 of the other 6 cases revascularization occurred and the end results were good.

Absorption of the femoral head. The capital femoral epiphysis was completely absorbed in 5 infants

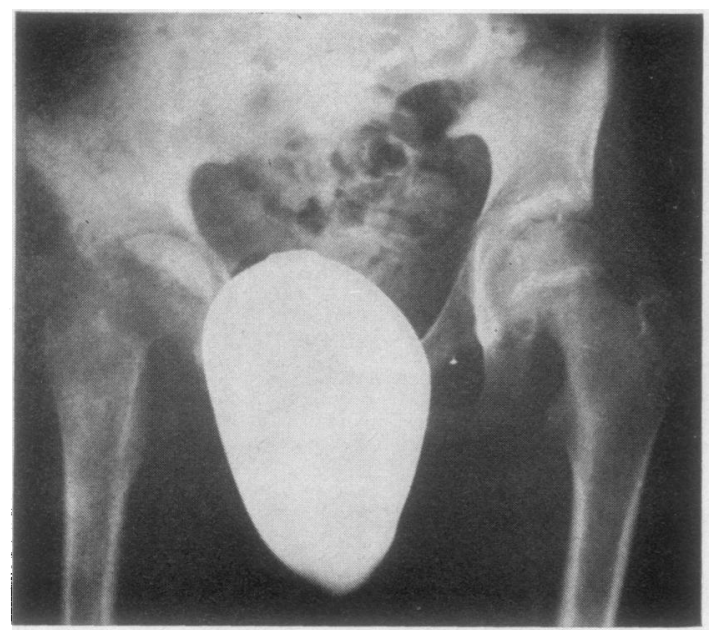

FIG. 5 Avascular necrosis of the right capital epiphysis in a 13-year-old boy. Diagnosis was greatly delayed because of an initial presentation with abdominal pain usually without preceding bone necrosis. Only one of these cases developed a normal hip. This boy's capital epiphysis completely disappeared when he was aged 6 months but he now has a clinically and radiologically normal hip 2 years later. The remaining. 4 cases failed to develop a normal epiphysis and were left with grossly disorganized hip joints.

Dislocation of the hip. Seven infants had dislocated hip joints in association with septic arthritis. Only 2 have a good outcome (Fig. 6) and one of these required a rotation osteotomy to contain the head. The other 5 cases all have destroyed hip joints (Fig. 7).

Coxa magna developed three times. Two of these hips are now clinically normal and show no radiological deterioration 14 and 17 years after the infection.

\section{FACTORS AFFECTING RESULT}

There was little difference in outcome between children and adults though the reasons differ. Most of the bad results in children result from destroyed hips, as discussed above, while many of the elderly patients failed to regain joint movement though there was little evidence of cartilage or bone destruction.

Infection with Staph. aureus gave only slightlyworse results than infection with other organisms. The difference is not significant. The effect of delay in diagnosis on the outcome is summarized in Table IX. It can be seen that most joints which remained untreated for more than a week tended to do worse than those treated within this time but the difference was not singificant $(P=0 \cdot 10)$.

It is not possible to deduce from this retrospective study which forms of treatment are most satisfactory. All patients were treated with systemic antibiotics. but the dosage and duration varied enormously. In addition, the degree of immobilization varied. Forty-seven patients were treated by open drainage while the remainder were treated conservatively. Regrettably it is not possible to compare the two groups as the policy determining surgical intervention differed.

Fifty-three patients had antibiotic instilled directly into the joint and 58 were treated by the systemic use of antibiotics only. Table $X$ shows that the outcome was similar and statistical analysis indicates that the use of intra-articular antibiotics had no. effect on the outcome.

\section{Discussion}

There are several factors which emerge from this study of the pattern of septic arthritis over 30 years. There seems to have been no striking overall change in the incidence although more cases are being seen among the elderly. Staph. aureus remains the most 
common causative organism but the variety of other organisms isolated in recent years has been increasing. Only two cases of $H$. influenzae have been found in this series. It would therefore seem wise to defer treatment while attempts are made to culture the

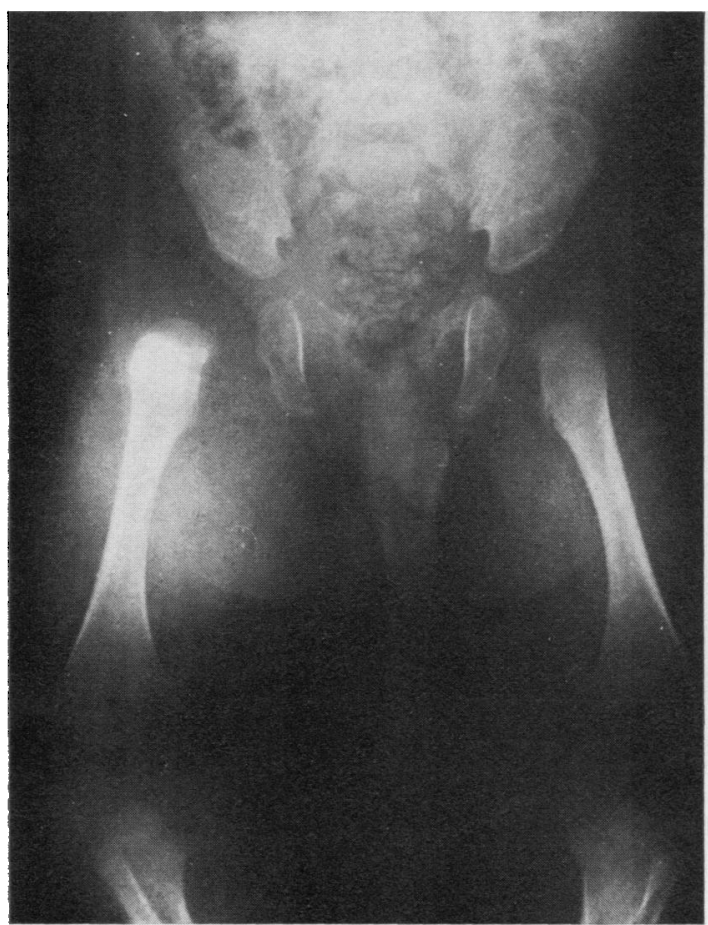

(a) responsible organism but then to start therapy immediately with an antistaphylococcal drug.

There are several possible reasons why patients tend to be less ill on admission. First, the infection is frequently modified by prior use of antibiotics; secondly, the patients are being seen in hospital earlier; and thirdly, some of the causative organisms seem to cause less systemic illness. These factors make early recognition of the disease more difficult.

Several authors (Ward, Cohen, and Bauer 1960; Paterson 1970; Lindgren and Lindberg 1973) have shown that delay in diagnosis worsens the prognosis. This is in keeping with the present series although there are a few instances where the diagnosis was greatly delayed and yet the outcome was good. Presumably the responsible organisms were of low virulence. Conversely, patients who present with marked systemic illness are more likely to suffer from permanent damage to the affected joint.

Before the advent of antibiotics, septic arthritis carried a substantial mortality. Badgley and others (1936) reported a $12 \%$ mortality and Heberling (1941) a $9 \%$ mortality. One would imagine that death from a pyogenic infection should now be preventable. However, although there was only one death in this series and Lindgren and Lindberg (1973) reported no deaths, others have been less fortunate. Russell and Ansell (1972) had two deaths in 28 cases, while Kelly and others (1970) reported a $19 \%$ mortality in their series of 78 cases. The continuing mortality from septic arthritis probably relates to the rising age incidence and the vulnerability of the elderly.

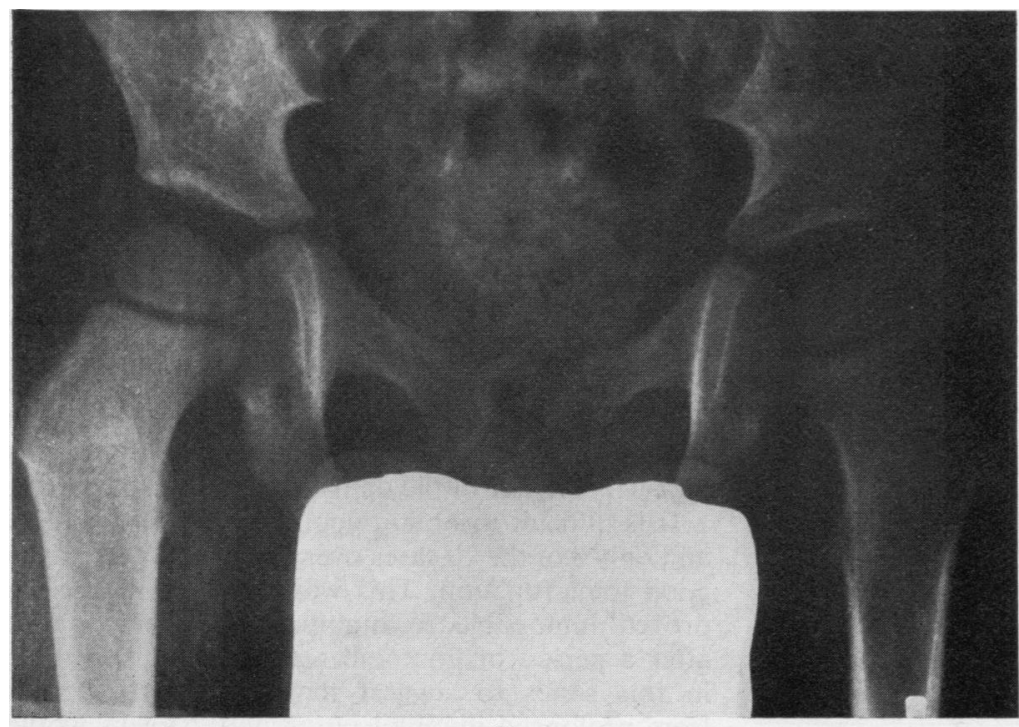

(b)

FIG. 6 (a) This infant's right hip is subluxed due to septic arthritis. (b) 2 years later the hip appears normal 


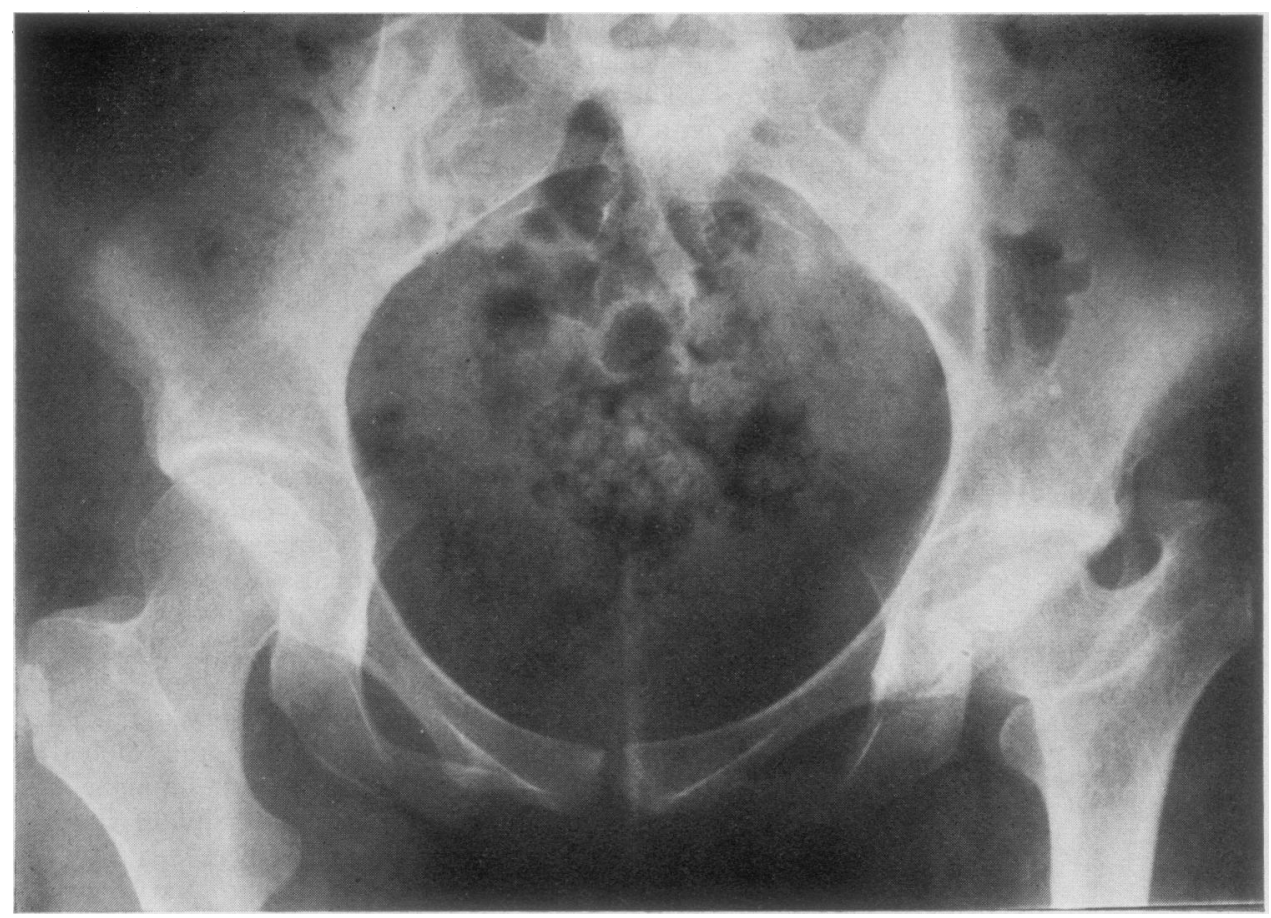

FIG. 7 Infantile septic arthritis resulting in dislocation and absorption of the left femoral epiphysis

Table IX Effect of delay in diagnosis on outcome

\begin{tabular}{|c|c|c|c|c|}
\hline & \multicolumn{2}{|c|}{ Delay $<1$ week } & \multicolumn{2}{|c|}{ Delay $>1$ week } \\
\hline & Good & Bad & Good & Bad \\
\hline $\begin{array}{l}\text { Infants' hips } \\
\text { Children's hips } \\
\text { Adult hips }\end{array}$ & $\begin{array}{r}2 \\
11 \\
6\end{array}$ & $\begin{array}{l}1 \\
2 \\
2\end{array}$ & $\begin{array}{r}1 \\
10 \\
6\end{array}$ & $\begin{array}{l}4 \\
2 \\
7\end{array}$ \\
\hline All hips & 19 & 5 & 17 & 13 \\
\hline $\begin{array}{l}\text { Children's knees } \\
\text { Adult knees }\end{array}$ & $\begin{array}{r}4 \\
14\end{array}$ & $\begin{array}{l}1 \\
3\end{array}$ & $\begin{array}{l}6 \\
7\end{array}$ & $\begin{array}{l}0 \\
4\end{array}$ \\
\hline All knees & 18 & 4 & 13 & 4 \\
\hline $\begin{array}{l}\text { Ankles } \\
\text { Upper limbs }\end{array}$ & $\begin{array}{l}4 \\
4\end{array}$ & 3 & $\begin{array}{l}2 \\
3\end{array}$ & $\begin{array}{l}\mathbf{1} \\
\mathbf{3}\end{array}$ \\
\hline Total & 45 & 12 & 35 & 21 \\
\hline
\end{tabular}

Table X Effect of local antibiotics on outcome

\begin{tabular}{|c|c|c|}
\hline & $\begin{array}{l}\text { Good } \\
\text { result }\end{array}$ & $\begin{array}{l}\text { Bad } \\
\text { result }\end{array}$ \\
\hline $\begin{array}{l}\text { Intra-articular antibiotic used } \\
\text { Intra-articular antibiotic not used }\end{array}$ & $\begin{array}{l}40 \\
38\end{array}$ & $\begin{array}{l}13 \\
20\end{array}$ \\
\hline
\end{tabular}

Septic arthritis of the hip has a higher frequency of bad results than infection of a knee joint. There is no evidence to suggest that either greater toxicity or a more delayed diagnosis is responsible for the difference. It seems likely that they result from pressure within the hip joint which interferes with the blood supply to the femoral capital epiphysis. Early decompression of infected children's hip joints is therefore essential. In Badgley's series, reported before antibiotics, dislocation of the hip always resulted in a poor outcome. However, EyreBrooks (1960) has shown that good results can be obtained even when the hip has dislocated and Lloyd-Roberts (1960) has stressed that the outcome can sometimes be better than one would anticipate from the radiographs. The good results obtained in this series following dislocation probably reflect the value of prolonged containment of the child's hips while repair of the damaged epiphysis occurred.

It is difficult to obtain good results in the elderly and only 8 of the 20 cases over the age of 60 regained good joint function. This was generally because it proved impossible to mobilize the affected joint after a period of immobilization. There is nothing in this series to suggest that the elderly benefit from prolonged immobilization and 2 weeks would seem to be adequate, provided a satisfactory response has been obtained to antibiotic therapy and radio- 
graphs show no secondary focus of bone infection. In younger patients joint mobility is more easily regained and the advantages of allowing the joint to become completely quiescent with a period of 6 weeks' immobilization seem to outweigh the problems of regaining motion.

It has been shown that bactericidal antibiotic levels can easily be achieved in synovial fluid after systemic administration (Parker and Schmidt 1971; Nelson 1972; Newman 1974). Argen, Wilson, and Wood (1966) report a persistent synovitis after intra-articular injections of penicillin, and Dionne and Cruess (1968) have produced similar changes experimentally with other antibiotics. This series has shown that there is no therapeutic advantage to be gained from the use of intra-articular antibiotics, and since a persistent synovitis can result there seems to be no justification for their intraarticular use in high doses.

The place of surgery in the treatment of septic arthritis is debatable. Paterson (1970) strongly favours operative treatment for infection in infants' hips and the frequency with which the blood supply to the capital epiphysis is interrupted supports this view. Goldenberg and others (1975) favour medical treatment without initially resorting to surgery.
It is regrettably not possible to deduce from this retrospective study whether initial surgical drainage is beneficial because the indications for operation varied. However, there were a number of cases where infection persisted despite antibiotics and aspiration. These cases eventually settled with surgical drainage of the joint and it is therefore important to be able to examine the joint readily until the infection subsides.

Although septic arthritis remains a serious condition with a high morbidity, modern treatment with antibiotics and immobilization gives much better results than wide drainage and active movement recommended by Heberling (1941). Many problems both in diagnosis and in treatment remain, but the fears of Watkins, Samilson, and Winters (1956) that antibiotics might cause delay in diagnosis, and thus worse results, seem unfounded. It is important to recognize the condition and start treatment early in the disease, and provided this is done a good result can be expected. If a good initial result is obtained there is no reason to suppose that the joint will deteriorate over subsequent years and that osteoarthrosis will result. Such a course of events was not seen in this series.

I am grateful to the surgeons of the Nuffield Orthopaedic Centre, Oxford, for allowing me to review their patients.

\section{References}

AlmQuist, E. E. (1970) Clin. Orthop., 68, 96 (The changing epidemiology of septic arthritis in children)

ARGEN, R. J., Wilson, C. H., AND Wood, P. (1966) Arch. intern. Med., 117, 661 (Suppurative arthritis)

Badgley, C. E., Yglesias, L., Perham, W. S., and Snyder, C. H. (1936) J. Bone Jt Surg., 18, 1047 (Study of the end results in 113 cases of septic hips)

DiONNE, R. C., AND CRUeSS, R. L. (1968) Ibid., 50B, 434 (The effects of intra-articular antibiotics)

Eyre-Brooks, A. L. (1960) Ibid., 42B, 11 (Septic arthritis of the hip and osteomyelitis of the upper end of the femur in infants)

Goldenderg, D. L., Brandt, K. D., Cohen, A. S., and CathCart, E. S. (1975) Arthr. and Rheum., 18, 83 (Treatment of septic arthritis)

Heberling, J. A. (1941) J. Bone Jt Surg. 23, 917 (A review of 201 cases of suppurative arthritis)

Kelly, P. J., Martin, W. J., AND Coventry, M. B. (1970) Ibid., 52A, 1595 (Bacterial suppurative arthritis in the adult)

LiNDGRen, L., AND LiNDBERG, L. (1973) Acta orthop. scand., 44, 263 (Twenty-nine cases of bacterial arthritis)

LloYd-RoBerTs, G. C. (1960) J. Bone Jt Surg., 42B, 706 (Suppurative arthritis of infancy)

Nelson, J. D. (1972) Pediatrics, 50, 437 (The bacterial etiology and antibiotic management of septic arthritis in infants and children)

Newman, J. H. (1974) Brit. med. J., 3, 472 (Cloxacillin levels in synovial fluid)

PARKer, R. H., AND SCHMIDT, F. R. (1971) Arthr. and Rheum., 14, 96 (Antibacterial activity of synovial fluid during therapy of septic arthritis)

Paterson, D. C. (1970) J. Bone Jt Surg., 52B, 474 (Septic arthritis in infancy and childhood)

Russell, A. S., AND ANSell, B. M. (1972) Ann. rheum. Dis., 31, 40 (Septic arthritis)

SALTER, R. B. (1970) 'Textbook of Disorders and Injuries of the Musculo-skeletal System', p. 164. Williams and Wilkins, Baltimore

Ward, J., CoHen, A. S., ANd Bauer, W. (1960) Arthr. and Rheum., 3, 522 (The diagnosis and therapy of acute suppurative arthritis)

Watkins, M. B., SAmilson, R. L., AND Winters, D. M. (1956) J. Bone Jt Surg., 38A, 1313 (Acute suppurative arthritis) 